http://jmscr.igmpublication.org/home/ ISSN (e)-2347-176x ISSN (p) 2455-0450

crossref DOI: https://dx.doi.org/10.18535/jmscr/v8i3.07

\title{
Status of Glycaemic Control in Patients Attending Endocrine OPD in a Tertiary Care Hospital in Bangladesh
}

\author{
Authors \\ Dr Indrajit Prasad ${ }^{1 *}$, Dr Joysree Saha ${ }^{2}$, Dr Sujit Kumar Sarker ${ }^{3}$, \\ Prof. Dr Md Hafizur Rahman ${ }^{4}$, Dr Ajit Kumar Paul, Dr Debesh Chandra Talukder ${ }^{6}$ \\ ${ }^{1}$ Associate Professor, Department of Endocrinology, Dhaka Medical College, Dhaka \\ ${ }^{2}$ Associate Professor, Department of Gynecology \& Obs. Popular Medical College Dhaka \\ ${ }^{3}$ Assistant Professor, Department of Ophthalmology, National institute of Ophthalmology, Dhaka \\ ${ }^{4}$ Professor, Department of Endocrinology, Dhaka Medical College, Dhaka \\ ${ }^{5}$ Associate Professor, Department of Endocrinology, Mainamoti Medical College, Comilla \\ ${ }^{6}$ Associate Professor, Department of ENT \& Head neck Surgery, Dhaka Medical College \\ *Corresponding Author \\ Dr Indrajit Prasad
}

\begin{abstract}
Strict glycaemic control early in the treatment process has been shown to reduce the occurrence of microand macro-vascular complications of diabetes in the long-term. Thus, treatment guidelines advise early intensification of treatment to achieve glycaemic control goals. However, evidence in Bangladesh suggests that, despite guideline recommendations, glycaemic control among patients with T2DM remains challenging. The objective of this study was to determinants of glycaemic control among individuals with type 2 diabetes mellitus patients in Bangladesh. A cross-sectional study was conducted during March to September 2017 at Endocrinology OPD in Lab Aid Specialized Hospital, Dhaka, Bangladesh. A total number of 213 patients with type 2 diabetes mellitus patients were enrolled. Information was gathered from patients by means of eye to eye meet, and their clinical records were explored. Numerous calculated relapse examinations were performed. Among the patients, $46.48 \%$ were male. Mean age was 49.20and standard deviation ( \pm 13.04$)$. Mean of HbAlc was $8.71 \%$ and standard deviation was ( \pm 3.97$)$. Low training level, rustic living arrangement, undesirable dietary patterns, insulin use rate follow up registration related with insufficient and exceptionally poor controls. Being female and smokeless tobacco buyer gave off an impression of being related with deficient control anyway psychological debilitation was related with poor control as it were. Commonness of insufficient glycaemic level was exceptionally high in Bangladesh. Having comprehended relatable way of life change variables, socioeconomics and co-morbidities among individuals with type 2 diabetes, human services suppliers related to patients should cooperate to address the glycaemic control.

Keywords: Glycaemic control, Endocrine OPD, Co-morbidities.
\end{abstract}

\section{Introduction}

Diabetes has been identified as one of the most common disease suffered by the vast majority of
Bangladesh. It was evaluated that, in the year 2017, in excess of 425 million individuals universally were experiencing diabetes, and still 
increasing day by day in low-and center salary nations, where about $80 \%$ of complete diabetes passing on the planet occurs ${ }^{[1]}$. In Bangladesh, the diabetes was detected in $9.7 \%$ of the total populace in $2011^{[2]}$, and the quantity is anticipated to be 13.7 million by $2045^{[1]}$.

The most significant part of the ideal administration of patients experiencing diabetes is counteraction of the harmful impacts of hyperglycemia. Glycaemic control is hence considered as the fundamental remedial objective for counteraction of these serious results. Results from numerous observational investigations and randomized controlled clinical trials ${ }^{[3-6]}$ have found that exacting control of glycaemic levels assists with forestalling confusions, particularly of the microvascular type ${ }^{[1]}$.Therefore, the overall aim of the present study is to status of glycaemic control in patients attending endocrine OPD in a tertiary care hospital in Bangladesh, especially among patients with T2DM.

\section{Materials \& Methods \\ Study Type}

This was a cross-sectional observational study. All outpatient subjects, who were older than 18years, diagnosed with T2DM and scheduled for a routine office visit during the time period between March to September 2017, were eligible to participate.

\section{Data Collection}

The primary data was collected from the patients who showed symptoms of diabetes were already diagnosed with diabetes. Additional data were also collected during follow up consultations, if patients visited more than once at OPD during the study period. A questionnaire survey was conducted in order to glean some of the additional information from the samples. The patients were given consent from to maintain the ethical validation of this study.

\section{Operational definition}

The patient's latest readings (within the previous three months) of glycaemic status were categorized as follows: good glycaemic control $=\mathrm{HbA} 1 \mathrm{c}<7 \%{ }^{[7-8]} ; 18.50-24.99=$ normal; $>25.00=$ overweight or obese ${ }^{[9]}$. The cut-off point for WHR was defined as a ratio of $>0.90$ for men and $>0.80$ for women. ${ }^{[10]}$

\section{Analysis Method}

Expressive measurements were accounted for utilizing mean with standard deviation (SD) for numerical information and relative frequencies (rates) for unmitigated information. To test the relationship between hazard factors and levels of glycaemic control, ANOVA, chi-square tests, and straightforward calculated relapse investigation were utilized for a univariate examination.

\section{Results}

Out of 213 patients, 99 (46.48\%) were male and female $114(53.52 \%)$. The mean $( \pm \mathrm{SD})$ age was $49.20( \pm 13.04)$ years and the mean $( \pm$ SD) duration of participants' diabetes conditions was 97.28 $( \pm 7.2)$ months. The mean $( \pm \mathrm{SD})$ BMI was 25.7 $( \pm 4.9) \mathrm{kg} / \mathrm{m}^{2}$ and the mean $( \pm \mathrm{SD}) \mathrm{HbA1c}$ was $8.71 \%( \pm 2.2 \%)$. Only $18.8 \%$ of participants were classified as having good control, $19.78 \%$ had fair control, $62 \%$ had poor glycaemic control, and $54.7 \%$ had very poor control. Table 1 shows demographic and lifestyle characteristics for various glycaemic levels. The prevalence of poor control was higher among females $(p=0.003)$, participants with a lower level of education $(p=0.001)$, those living in rural areas $(p<0.001)$, and housewives $(p=0.011)$. Further, the prevalence of poor glycaemic control was higher among smokeless tobacco consumers $(p=0.008)$ and unhealthy diners $(\mathrm{p}=0.008)$. 
Table 1: Background information of the patients

\begin{tabular}{|l|c|c|c|}
\hline Characteristics & & Frequency & Percentage \\
\hline Religion & Islam & 180 & 84.51 \\
\hline \multirow{5}{*}{ Marital status } & Hinduism & 32 & 15.02 \\
\cline { 2 - 4 } & Christianity & 1 & 0.47 \\
\cline { 2 - 4 } & Buddhis & 0 & 0.00 \\
\hline Education & Base & $\mathbf{2 1 3}$ & $\mathbf{1 0 0 . 0 0}$ \\
\hline \multirow{5}{*}{} & Married & 203 & 95.31 \\
\cline { 2 - 4 } & Unmarried & 10 & 4.69 \\
\hline & Base & $\mathbf{2 1 3}$ & $\mathbf{1 0 0 . 0 0}$ \\
\cline { 2 - 4 } & Illiterate & 7 & 3.29 \\
\cline { 2 - 4 } & Primary & 22 & 10.33 \\
\cline { 2 - 4 } & SSC & 48 & 22.54 \\
\cline { 2 - 4 } & HSC & 26 & 12.21 \\
\cline { 2 - 4 } & Graduate & 83 & 38.97 \\
\cline { 2 - 4 } & Others & 27 & 12.68 \\
\hline
\end{tabular}

Demographic characteristics and lifestyle by glycaemic control

Gender of the patients

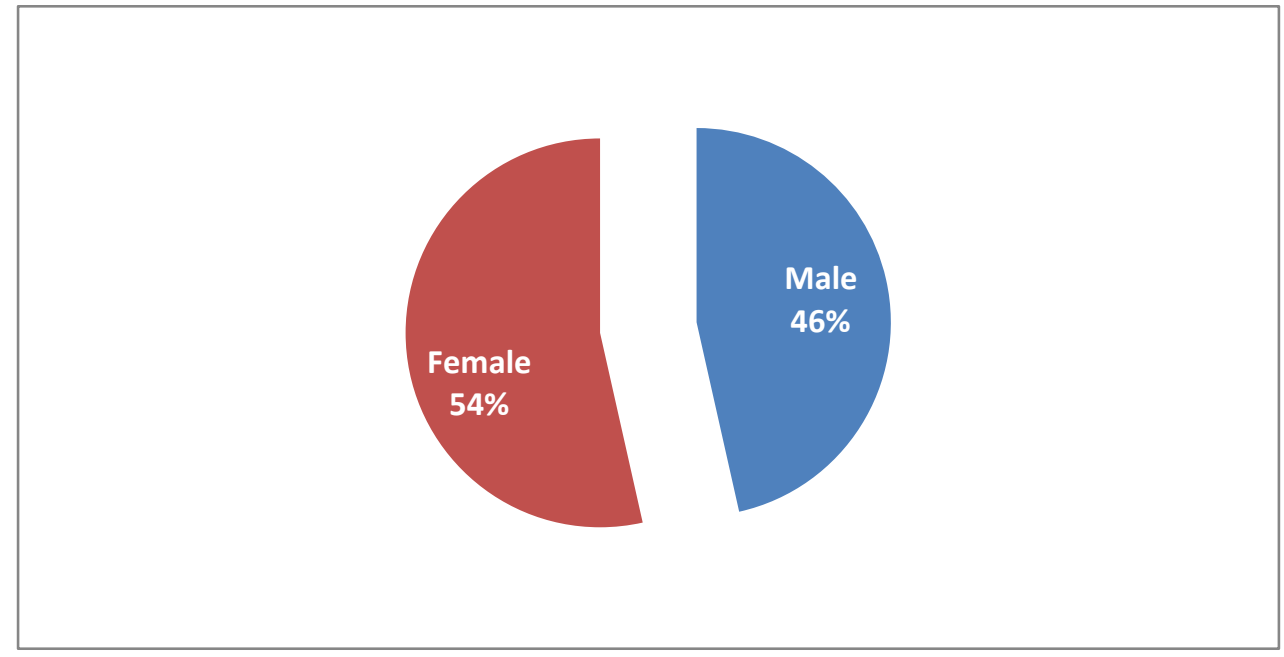

Figure 1: Gender of the patients

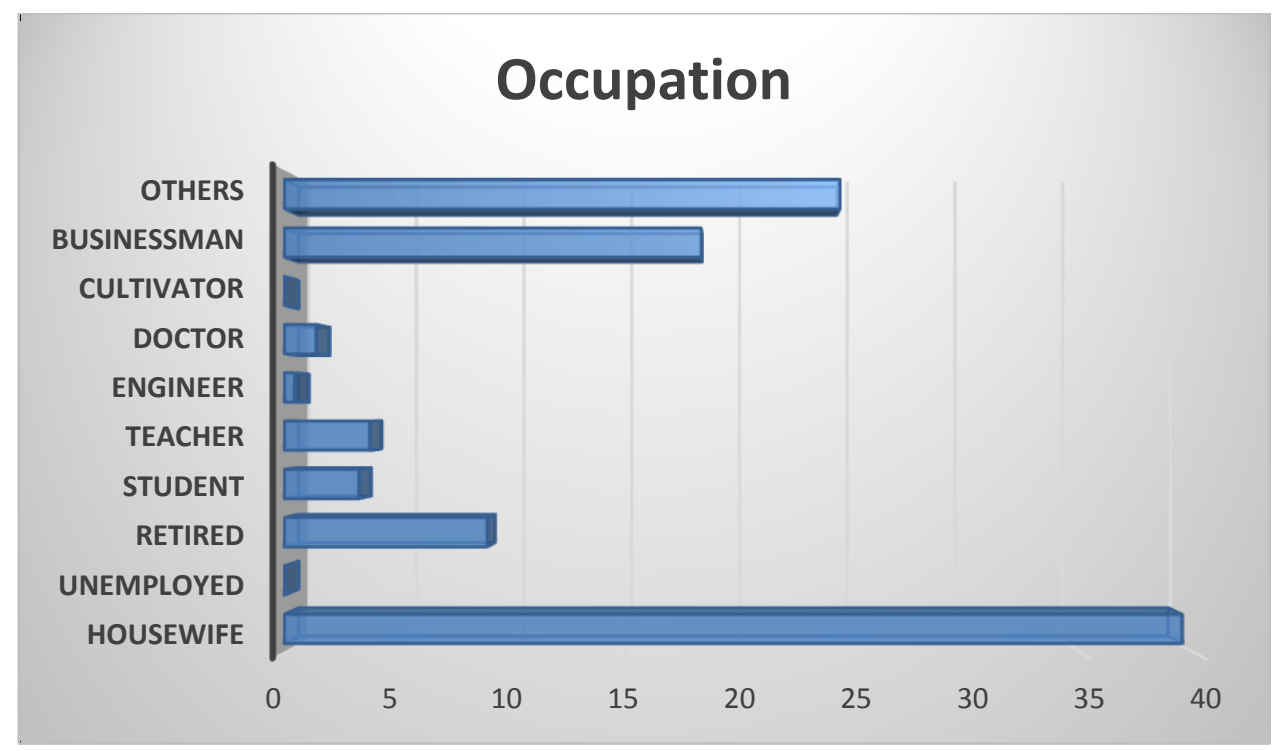

Figure: 2 Occupation of Patients 
The clinical conditions and their characteristics of the 213 samples by glycaemic control are described in Table 2, Table 3, and Table 4.

Table 2 Clinical characteristics by glycaemic control

\begin{tabular}{|l|c|c|c|}
\hline On anti-hypertensive medication & Yes & 117 & 54.93 \\
\hline & No & 86 & 40.38 \\
\hline $\begin{array}{l}\text { Recode of how patients check their blood } \\
\text { glucose at Home or Office }\end{array}$ & Blucometer & $\mathbf{2 0 3}$ & $\mathbf{9 5 . 3 1}$ \\
\hline & Hospital Lab & 35 & 82.32 \\
\hline Known Diabetes complications & Base & $\mathbf{1 9 8}$ & 17.68 \\
\hline & Retinopathy & 10 & 20.00 \\
\hline & Nephropathy & 13 & 26.00 \\
\hline & Neuropathy & 22 & 44.00 \\
\hline & CAD & 9 & 18.00 \\
\hline & CVA & 3 & 6.00 \\
\hline & PVD & 4 & 8.00 \\
\hline From where they took consultation for & ED(Male) & 11 & 22.00 \\
\hline diabetes & Private chamber & $\mathbf{5 0}$ & $\mathbf{1 0 0 . 0 0}$ \\
\hline & & 83.90 \\
\hline & OPD of hospital & 5 & 2.44 \\
\hline & Mixed & 28 & 13.66 \\
\hline
\end{tabular}

Table 3 Adjusted association (odds ratio (OR)) between risk factors and inadequate (HbA1c $\geq 7 \%$ ) glycaemic control by duration of diabetes

\begin{tabular}{|c|c|c|c|c|c|c|}
\hline & \multicolumn{3}{|c|}{ Diabetes duration $\leq 5$ years } & \multicolumn{3}{|c|}{ Diabetes duration $>5$ years } \\
\hline Variables & OR & $95 \% \mathrm{CI}$ & p-value & OR & $95 \% \mathrm{CI}$ & p-value \\
\hline Age (ref: $\leq 40$ years) & & & & & & \\
\hline \multicolumn{7}{|l|}{ 41-60 years } \\
\hline \multirow{2}{*}{\multicolumn{7}{|c|}{$\begin{array}{l}>\mathbf{6 0} \text { years } \\
\text { Gender (ref: male) }\end{array}$}} \\
\hline & & & & & & \\
\hline F & & & & 26 & $14-42$ & 0.001 \\
\hline \multicolumn{7}{|l|}{ Location (ref: urban) } \\
\hline Rural & 2.5 & $1.2-4.4$ & 0.002 & 2.6 & $1.5-4.7$ & 0.001 \\
\hline \multicolumn{7}{|c|}{ Smokeless tobacco (ref: never) } \\
\hline Ever consumer & 2.8 & $1.4-6.2$ & 0.007 & & & \\
\hline \multicolumn{7}{|c|}{ Eating habit (ref: Healthy) } \\
\hline Unhealthy & 3.1 & $1.3-6.8$ & 0.007 & 1.9 & $1.2-3.3$ & 0.24 \\
\hline \multicolumn{7}{|c|}{ Modality of treatment (ref: without insulin) } \\
\hline Insulin & 3.7 & $2.1-7.1$ & $<0.001$ & 4.1 & $2.6-6.5$ & $<0.001$ \\
\hline \multicolumn{7}{|c|}{ Follow up check-up frequency (ref: $\leq 3$ months) } \\
\hline \multicolumn{7}{|l|}{ Every six months } \\
\hline Annually & 2.7 & $1.2-5.6$ & 0.015 & 2.1 & $1.0-4.3$ & 0.042 \\
\hline \multicolumn{7}{|l|}{ CAD (ref: no) } \\
\hline Yes & 3.8 & $1.5-10.3$ & 0.005 & 1.9 & $1.1-3.2$ & 0.022 \\
\hline
\end{tabular}

\section{Discussion}

Glycaemic control is the foundation of overseeing T2DM and is basic for the anticipation of long haul diabetes inconveniences. When all is said in done, being female, a low degree of training, rustic living arrangement, smokeless tobacco utilization, unfortunate dietary patterns, insulin use, history of CAD, and psychological weakness 
were related with deficient glycaemic levels in the Bangladeshi T2DM populace.

The prevalence of inadequate glycaemic control found among people with T2DM is consistent with previous studies conducted in Bangladesh by Selim et al. ${ }^{[8]}$ and Latif et al. ${ }^{[11]}$. The proportion of people with inadequate glycaemic control is higher among females who have had the condition for a longer duration ( $>5$ years), which is also similar to the findings of the previous studies. ${ }^{[12,13]}$ The study showed that, adjusted association (odds ratio $(\mathrm{OR})$ ) between risk factors with inadequate glycaemic control (HbA1c $\geq 7 \%$ ), the sub-group (duration of T2DM: $\leq 5$ years, shorter and $>5$ years, longer) analysis results for inadequate and very poor glycaemic controls are presented in Tables 3. Table 3 shows that most of the variables in the multiple logistic model appeared as common risk factors between the two groups. However, smokeless tobacco consumption (OR: 2.8, 95\% CI: 1.4-6.2) presented a risk only in the shorter duration group and female participants (OR: 2.5; 95\% CI: 1.5-4.1) were at higher risk in the longer duration group only. Tobacco for the most part raises glucose levels, and the unfavorable impacts of smokeless tobacco on wellbeing are apparent from past investigations $^{[14]}$.

The majority of the current study's participants responded that they had received dietary advice from health professionals; however, they also stated that they were unable to maintain the advice. This may be due to a lack of understanding or low affordability of healthy foods. Also, we found that solitary $37.6 \%$ of our members utilized self-checking blood glucose gadgets; this demonstrates an absence of appropriate observing, implying that patients are probably going to battle with dealing with their insulin. The study explored all conceivable modifiable and non-modifiable components influencing glycaemic control, which adds solidarity to the discoveries. The enrollment of members and the data assortment strategies guaranteed information quality. In any case, this examination has the impediment of being crosssectional in configuration, implying that a worldly connection among circumstances and logical results can't be set up.

\section{Conclusion}

In conclusion, the extent of individuals with uncontrolled glycaemic levels is significantly high in Bangladesh, which may add to an expanding pervasiveness of inconveniences and in this manner may represent an additional weight on social insurance costs. This examination has distinguished various modifiable indicators of deficient glycaemic control: in particular, various arrangements of hazard factors were recognized for members who had been T2DM patients for various lengths. The investigation's discoveries underscore the significance of being agreeable with follow-up registration, and of way of life adjustments, including good dieting and evading smokeless tobacco utilization. A far reaching information on modifiable and non-modifiable hazard elements will assist wellbeing with caring suppliers to individualize the decision of glycaemic objectives in reference to term, with the point of improving consideration and results for patients with T2DM.

\section{References}

1. Afroz A, Ali L, Karim MN, et al. Glycaemic Control for People with Type 2 Diabetes Mellitus in Bangladesh - An urgent need for optimization of management plan. Sci Rep. 2019;9(1): 10248. Published 2019 Jul 15. doi:10.1038/s41598-019-46766-9

2. Akter, S., Rahman, M. M., Abe, S. K. \& Sultana, P. Prevalence of diabetes and prediabetes and their risk factors among Bangladeshi adults: a nationwide survey. Bulletin of the World Health Organization 92, 204-213A (2014).

3. Control, D. \& Group, C. T. R. The effect of intensive treatment of diabetes on the development and progression of long-term 
complications in insulin-dependent diabetes mellitus. $N$ Engl j Med 1993, 977-986 (1993).

4. Group, U. P. D. S. Intensive blood-glucose control with sulphonylureas or insulin compared with conventional treatment and risk of complications in patients with type 2 diabetes (UKPDS 33). The Lancet 352, 837-853 (1998).

5. Group, U. P. D. S. Effect of intensive blood-glucose control with metformin on complications in overweight patients with type 2 diabetes (UKPDS 34). The Lancet 352, 854-865 (1998).

6. Stettler, C. et al. Glycemic control and macrovascular disease in types 1 and 2 diabetes mellitus: meta-analysis of randomized trials. American heart journal 152, 27-38 (2006).

7. Sanal, T., Nair, N. \& Adhikari, P. Factors associated with poor control of type 2 diabetes mellitus: a systematic review and meta-analysis. Journal of diabetology 3, 110 (2011).

8. Selim, S., Pathan, F., Saifuddin, M., Latif, Z. \&Karim, N. The challenge of proper glycaemic control among patients with type 2 diabetes in Bangladesh. Sri Lanka Journal of Diabetes Endocrinology and Metabolism 6 (2016).

9. Harris, P. A. et al. Research electronic data capture (REDCap) - a metadata-driven methodology and workflow process for providing translational research informatics support. Journal of biomedical informatics 42, 377-381 (2009).
10. American Diabetes Association. Diabetes Care 38(Suppl.

1), S33-S34, https://doi.org/10.2337/dc15-S009 (2015).

11. Latif, Z., Jain, A. \&Rahman, M. Evaluation of management, control, complications and psychosocial aspects of diabetics in Bangladesh: DiabCare Bangladesh 2008. Bangladesh Medical Research Council Bulletin 37, 11-16 (2011).

12. Sanal, T., Nair, N. \&Adhikari, P. Factors associated with poor control of type 2 diabetes mellitus: a systematic review and meta-analysis. Journal of diabetology 3, 110 (2011).

13. Mendes, A. B. V., Fittipaldi, J. A. S., Neves, R. C. S., Chacra, A. R. \& Moreira, E. D. Prevalence and correlates of inadequate glycaemic control: results from a nationwide survey in 6,671 adults with diabetes in Brazil. Actadiabetologica 47, 137-145 (2010).

14. Gupta, P. C. \& Ray, C. S. Smokeless tobacco and health in India and South Asia. Respirology 8, 419-431 (2003). 